\title{
Methylene Blue
}

National Cancer Institute

\section{Source}

National Cancer Institute. Methylene Blue. NCI Thesaurus. Code C644.

A synthetic basic dye. Methylene blue stains to negatively charged cell components like nucleic acids; when administered in the lymphatic bed of a tumor during oncologic surgery, methylene blue may stain lymph nodes draining from the tumor, thereby aiding in the visual localization of tumor sentinel lymph nodes. When administered intravenously in low doses, this agent may convert methemog lobin to hemoglobin. 